\title{
Desempenho, consumo e morfometria in vivo de cordeiros Santa Inês alimentados com rações contendo torta de girassol em substituição ao farelo de algodão
}

\author{
[Performance, consumption and in vivo morphometry of Santa Inês lambs fed diets containing \\ sunflower cake in place of cottonseed meal] \\ F. Fernandes Júnior ${ }^{1}$, E.L.A. Ribeiro ${ }^{2}$, F.A.B. Castro $^{2}$, I.Y. Mizubuti ${ }^{2}$, L.D.F. Silva ${ }^{2}$, \\ E.S. Pereira ${ }^{3}$, A.P. Pinto ${ }^{3}$, M.A.A.F. Barbosa ${ }^{2}$, N.A. Koritiaki ${ }^{1}$ \\ ${ }^{1}$ Alunos de pós-graduação - Universidade Estadual de Londrina - UEL - Londrina, PR \\ ${ }^{2}$ Universidade Estadual de Londrina - UEL - Londrina, PR \\ ${ }^{3}$ Universidade Federal do Ceará - UFC - Fortaleza, CE
}

\begin{abstract}
RESUMO
Este estudo foi conduzido com o objetivo de determinar o melhor teor de substituição da proteína do farelo de algodão pela proteína da torta de girassol em dietas para cordeiros Santa Inês, por meio da avaliação do consumo, ganho de peso, conversão alimentar e medidas morfométricas. Foram confinados, por 60 dias, 30 cordeiros da raça Santa Inês, machos inteiros, com idade e peso médio no início do

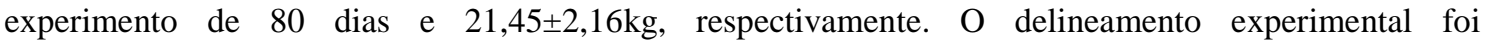
completamente casualizado, sendo os animais divididos em 5 tratamentos, com 6 repetições por tratamento, de acordo com a quantidade de proteína do farelo de algodão substituída pela proteína da torta de girassol $(0,20,40,60$ e $80 \%$ de substituição). As variáveis peso final, consumo de matéria seca e conversão alimentar não foram afetadas pelas dietas experimentais, embora o ganho médio diário tenha sido inferior para as dietas com maior teor de torta de girassol. Para os parâmetros de consumo, verificouse diferença apenas no consumo de extrato etéreo em relação ao peso metabólico $\left(\mathrm{g} / \mathrm{kg} \mathrm{PV} \mathrm{PV}^{0,75}\right.$ ), em que cordeiros recebendo dieta com maior teor de torta de girassol ingeriram maiores quantidades de extrato etéreo. Em relação às medidas morfométricas, houve decréscimo linear da altura de dorso e largura de garupa com a inclusão da torta de girassol na dieta. A substituição da proteína do farelo de algodão pela proteína da torta de girassol afetou negativamente o ganho de peso de cordeiros Santa Inês em confinamento. Porém, teve pouca ou nenhuma influência nos parâmetros de consumo e nas medidas morfométricas in vivo.
\end{abstract}

Palavras-chave: Biodiesel, coprodutos, confinamento, ovinos

\begin{abstract}
This study was conducted with the aim to determine the optimal level of protein replacement of cottonseed meal protein by sunflower cake in diets for Santa Inês lambs, through the evaluation of consumption, weight gain, feed conversion and morphometric measurements. Thirty Santa Inês lambs, bulls, with age and weight at the beginning of the experiment of 80 days and $21.45 \pm 2.16 \mathrm{~kg}$, respectively, were confined for 60 days. A completely randomized experimental design was used, where the animals were divided into 5 treatments with 6 replicates per treatment. For the treatments, the protein from the cottonseed meal was replaced by the protein of the sunflower cake (0, 20, 40, 60 and 80\% of substitutions). For morphometric determinations, the following measurements were taken: pre-slaughter body length, leg length, leg perimeter, height of the dorsum; hip height; chest girth, hip width and chest width. Final weight, dry matter intake and feed conversion were not affected by the experimental diets, although the average daily gain was lower for diets with higher content of sunflower cake. For consumption parameters, there was a difference only in the consumption of ether extract in relation to metabolic weight $(\mathrm{g} / \mathrm{kg} P V 0,75)$, where lambs receiving diets with higher levels of sunflower cake
\end{abstract}

Recebido em 26 de julho de 2013

Aceito em 4 de agosto de 2014

E-mail: ffjunior_zoo@hotmail.com 
ingested larger amounts of ether extract. Regarding the morphometric measurements, there was a linear decrease of the height of the dorsum and hip width with the inclusion of sunflower cake in the diet. The replacement of cottonseed meal protein by sunflower cake protein negatively affected the weight gain of Santa Inês lambs. However, it affected little or nothing the parameters of consumption and in vivo morphometric measurements.

Keywords: biodiesel, coproducts, feedlot, sheep

\section{INTRODUÇÃO}

Com a crescente demanda pela carne ovina, passou a existir a procura por melhorias nos sistemas de produção, especialmente no que se refere ao desempenho e qualidade da carne de cordeiros, em que a utilização da terminação intensiva pode contribuir para o melhor controle sanitário e nutricional dessa categoria animal (Madruga et al., 2005).

No entanto, as maiores desvantagens se encontram nos altos custos de produção, principalmente relacionados à alimentação. A utilização de coprodutos gerados a partir de desenvolvimentos tecnológicos da cadeia do biodiesel é uma alternativa para possibilitar que os animais atinjam o máximo do seu potencial de produção com baixo custo e, ao mesmo tempo, solucionando eventuais problemas ambientais, oriundos da geração de biodiesel (Agy et al., 2012; Goes et al., 2012).

O girassol (Helianthus annus L.) apresenta viabilidades técnica e ambiental na produção de biocombustíveis, gerando a torta e o farelo, coprodutos da extração do óleo (Backes et al., 2008). A torta de girassol apresenta possibilidades de aplicação na alimentação animal, por sua fácil obtenção na propriedade, no processo de produção do óleo bruto combustível. Estudos utilizando torta de girassol na dieta de bovinos de corte (Goes et al., 2012), caprinos (Dutta et al., 2002) e ovinos (Ahmed e Abdalla, 2005) demonstraram resultados satisfatórios de ganho de peso e consumo de alimentos.

De maneira geral, a torta de girassol pode ser considerada uma fonte alternativa de proteína $(>200 \mathrm{~g} / \mathrm{kg}$ de MS de proteína bruta), apresentando em torno de $800 \mathrm{~g} / \mathrm{kg}$ de $\mathrm{MS}$ de nutrientes digestíveis totais e lipídios superiores a 150g/kg de MS (Beran et al., 2007).

Em um sistema de produção de carne, o consumo de alimentos é fundamental para atender às exigências de uma determinada categoria, influenciando no desenvolvimento corporal do animal, o qual também pode ser caracterizado com o uso de medidas morfométricas in vivo, permitindo correlacionar com o peso vivo, indicando ainda características produtivas e determinação da idade ao abate (Costa Junior et al., 2006).

Nesta pesquisa, avaliaram-se os efeitos da inclusão da proteína da torta de girassol em substituição à proteína do farelo de algodão na ração sobre os parâmetros de desempenho, consumo e medidas morfométricas in vivo de cordeiros Santa Inês terminados em confinamento.

\section{MATERIAL E MÉTODOS}

O experimento foi realizado no setor de ovinocultura da Fazenda Escola da Universidade Estadual de Londrina (FAZESC-UEL), conduzido de acordo com as normas éticas e aprovado pelo Comitê de Ética em Experimentação Animal da mesma instituição, registrado no CEEA/UEL sob o $\mathrm{n}^{\circ} 60 / 10$, processo $n^{\circ} 123 / 2010$. O período experimental compreendeu os meses de agosto a novembro de 2011. Foram utilizados 30 cordeiros da raça Santa Inês, machos, inteiros, com idade e peso médio no início do experimento de 80 dias e $21,45 \pm 2,16 \mathrm{~kg}$, respectivamente.

No início do experimento, os animais foram pesados, identificados, vacinados contra clostridioses, vermifugados e distribuídos aleatoriamente, dois a dois, em baias $(1,3 \mathrm{x}$ $2,0 \mathrm{~m}) \mathrm{em}$ aprisco coberto e com piso ripado, em regime de confinamento durante 60 dias, precedidos de sete dias de adaptação às condições experimentais. $\mathrm{O}$ delineamento experimental foi completamente ao acaso, sendo os animais divididos em cinco tratamentos, com seis repetições por tratamento, de acordo com a quantidade de proteína da torta de girassol em 
substituição à proteína do farelo de algodão na ração $(0,20,40,60$ e $80 \%$ de substituição).

$\mathrm{O}$ arraçoamento era feito duas vezes ao dia, às 7 e às 16 horas, na forma total (volume de silagem de sorgo + concentrado). As sobras foram pesadas diariamente e a quantidade de ração ofertada foi ajustada de acordo com o consumo do dia anterior, permitindo sobras de $20 \%$ do total oferecido da ração em MS. Os cordeiros tinham acesso irrestrito à água.
As rações utilizadas no experimento foram calculadas após análise bromatológica dos alimentos (Tab. 1), realizada no Laboratório de Nutrição Animal da Universidade Estadual de Londrina. As determinações de MS, proteína bruta (PB), matéria mineral (MM), extrato etéreo (EE), fibra em detergente neutro (FDN), fibra em detergente ácido (FDA) e fibra bruta (FB) (para estimativa de NDT) foram realizadas segundo procedimentos citados por Mizubuti et al. (2009).

Tabela 1. Composição químico-bromatológica dos ingredientes das rações experimentais

\begin{tabular}{lccccccc}
\hline \multirow{2}{*}{\multicolumn{1}{c}{ Ingredientes }} & $\begin{array}{c}\text { Componentes nutritivos } \\
\text { MS }\end{array}$ & $\begin{array}{c}\text { MM } \\
\text { g/kg MN }\end{array}$ & $\begin{array}{c}\text { PB } \\
\text { gg MS }\end{array}$ & $\begin{array}{c}\text { EE } / \mathrm{kg} \mathrm{MS} \\
\text { g/kg MS }\end{array}$ & $\begin{array}{c}\text { FDN } \\
\text { g/kg MS }\end{array}$ & $\begin{array}{c}\text { FDA } \\
\text { g/kg MS }\end{array}$ & $\begin{array}{c}\text { NDT } \\
\text { g/kg MS }\end{array}$ \\
\hline Silagem sorgo & 279,30 & 58,20 & 86,80 & 19,00 & 673,4 & 429,00 & 550,30 \\
Milho triturado & 875,30 & 15,40 & 83,10 & 29,20 & 179,6 & 26,00 & 817,40 \\
Torta de girassol & 921,10 & 55,10 & 257,60 & 196,10 & 369,4 & 225,40 & 803,70 \\
Farelo de algodão & 915,40 & 49,70 & 318,90 & 68,80 & 485,2 & 317,40 & 620,10 \\
Fosfato bicálcico & 990,00 & & & & & & \\
Cálcario calcítico & 990,00 & & & & & & \\
Mineral & 990,00 & & & & & & \\
\hline
\end{tabular}

Os teores de nutrientes digestíveis totais (NDT) dos alimentos utilizados para o balanceamento das dietas foram estimados pelas seguintes equações propostas por Kearl (1982): Alimentos energéticos $=40,2625+0,1969(\% \mathrm{~PB})+$ $0,4228(\% \mathrm{ENN})+1,1903(\% \mathrm{EE})+0,1379(\% \mathrm{FB})$ alimentos proteicos $=40,3227+0,5398(\% \mathrm{~PB})+$ $0,4448(\% \mathrm{ENN})+1,4218(\% \mathrm{EE})-0,7007(\% \mathrm{FB})$; silagem de volumosos $=\%$ NDT $=-21,9391+$ $1,0538(\% \mathrm{~PB})+0,9736(\% \mathrm{ENN})+3,0016(\% \mathrm{EE})$ $+0,4590(\% \mathrm{FB})$.

As rações eram isoproteicas e continham silagem de sorgo e concentrado composto por farelo de algodão, milho grão triturado, torta de girassol, fosfato bicálcico, calcário calcítico e sal mineral, com relação volumoso:concentrado de 34:66 elaboradas para cordeiros de maturação tardia, $20 \mathrm{~kg}$ de peso corporal e ganho de $0,200 \mathrm{~kg} / \mathrm{dia}$, com base no NRC (National..., 2007) (Tab. 2).

Foram realizadas coletas semanais das rações ofertadas e das sobras, sendo estas acondicionadas em sacos de papel e levadas a estufa com ventilação forçada a $55^{\circ} \mathrm{C}$, por 72 horas para pré-secagem. Posteriormente, as amostras foram moídas em moinho com peneira de $1 \mathrm{~mm}$ de diâmetro, sendo feitas amostras compostas de cada tratamento por período, conservadas e previamente identificadas para determinação de MS, PB, EE, MM, FDN e FDA.

Para estimativa do consumo de MS, foram realizadas pesagens diárias, por baia, da ração ofertada e das sobras. Os totais do ofertado e sobras da ração foram divididos pelo número de dias em confinamento (60), resultando na média diária de ofertados e sobras.

Com os valores de MS, determinaram-se as quantidades médias de MS ofertada e MS das sobras e, por diferença entre esses valores, obteve-se o consumo médio diário de MS por baia (CMS). Para obtenção do CMS e dos demais componentes nutritivos, dividiu-se o consumo observado pelo número de animais na baia. Foram avaliadas as ingestões de MS, MM, PB, FDN, FDA, EE e de NDT, expressas em grama/animal/dia, em percentagem de peso corporal (\% do PC) e em peso metabólico $\left(\mathrm{PV}^{0,75}\right)$. 
Tabela 2. Proporções dos ingredientes e composição das rações experimentais

\begin{tabular}{|c|c|c|c|c|c|}
\hline \multirow{2}{*}{ Ingredientes (g/kg MS) } & \multicolumn{5}{|c|}{ Teores de torta de girassol $(\%)$} \\
\hline & 0 & 20 & 40 & 60 & 80 \\
\hline Silagem sorgo & 343,00 & 343,00 & 344,00 & 343,70 & 343,60 \\
\hline Milho & 193,16 & 160,57 & 127,59 & 94,90 & 61,89 \\
\hline Torta de girassol & 0,00 & 112,48 & 224,94 & 337,60 & 449,89 \\
\hline Farelo de algodão & 446,76 & 366,67 & 286,08 & 205,29 & 124,50 \\
\hline Fosfato bicálcico & 0,00 & 0,00 & 0,00 & 2,49 & 6,37 \\
\hline Cálcario calcítico & 10,51 & 10,71 & 10,89 & 9,39 & 7,02 \\
\hline Mineral $^{1}$ & 6,57 & 6,57 & 6,56 & 6,56 & 6,56 \\
\hline \multicolumn{6}{|l|}{ Composição nutricional } \\
\hline Matéria seca $(\mathrm{g} / \mathrm{kg} \mathrm{MN})$ & 482,50 & 500,30 & 501,80 & 517,50 & 491,00 \\
\hline Matéria mineral (g/kg MS) & 67,00 & 68,10 & 67,20 & 70,80 & 69,80 \\
\hline Proteína bruta (g/kg MS) & 206,50 & 206,30 & 194,70 & 195,40 & 191,50 \\
\hline Extrato etéreo (g/kg MS) & 55,70 & 67,00 & 72,70 & 88,40 & 95,40 \\
\hline Fibra detergente neutro (g/kg MS) & 452,70 & 431,10 & 419,40 & 404,80 & 417,30 \\
\hline Fibra detergente ácido (g/kg MS) & 263,90 & 249,30 & 280,90 & 257,90 & 298,00 \\
\hline Nutrientes digestíveis totais (g/kg MS) & 623,40 & 637,80 & 651,60 & 665,10 & 678,30 \\
\hline
\end{tabular}

${ }^{\mathrm{T}}$ Mineral: Cálcio 128g; Enxofre 10,00g; Fósforo 60,00g; Magnésio 6.000,00mg; Sódio 152,00mg; Cobalto 50,00mg; Ferro 1.400,00mg; Iodo 74,00mg; Manganês 1.820,00mg; Selênio 15,00mg; Zinco $2.730 \mathrm{mg}$; Flúor $600,00 \mathrm{mg}$.

Ao final do período experimental, foi feita pesagem, precedida por jejum de 16 horas, para obtenção do peso vivo final, do ganho de peso médio diário e da conversão alimentar. A conversão alimentar foi calculada pela razão entre os consumos da ração e o ganho de peso diário.

Determinou-se a condição corporal antes do abate, por meio da palpação da região lombar, conferindo-se nota de 1,00 a 5,00 (1,00 para pior e 5,00 para a melhor), de acordo com a metodologia descrita por Osório e Osório (2005).

Para os cálculos morfométricos, foram aferidas as seguintes medidas pré-abate, adaptadas de Yáñez et al. (2004) e Cézar e Souza (2007): comprimento corporal, comprimento da perna, perímetro da perna, altura do dorso, altura da garupa, perímetro torácico, largura da garupa e largura de peito. As mensurações foram feitas com os animais em estação forçada, isto é, membros, anterior e posterior, na perpendicular sobre um piso plano e cimentado. As medidas foram obtidas pelo mesmo observador e sempre do lado direito do animal, utilizando-se fita métrica e esquadro de madeira.

Estimou-se também a compacidade corporal (IC), índice objetivo da conformação in vivo, obtido pela fórmula: IC $=$ peso vivo final/comprimento corporal $(\mathrm{kg} / \mathrm{cm}) \quad($ Costa Junior et al., 2006).

Os dados obtidos foram submetidos à análise de variância, e quando significativo à regressão polinomial, considerando-se o nível de significância de 5\% (Statistical..., 2001).

\section{RESULTADOS E DISCUSSÃO}

Os valores observados para o ganho de peso médio diário foram de 0,$252 ; 0,204 ; 0,182 ; 0,153$ e $0,123 \mathrm{~kg} / \mathrm{dia}$ para os animais das dietas experimentais com $0 ; 20 ; 40 ; 60$ e $80 \%$ de torta de girassol, respectivamente (Tab. 3). Houve efeito linear negativo $(\mathrm{P}<0,05)$ para essa variável, sendo que os teores de 0,$0 ; 20,0$ e $40,0 \%$ de substituição da proteína do farelo de algodão por proteína da torta de girassol mostraram ganhos próximos ao esperado, que era de $0,200 \mathrm{~kg} / \mathrm{animal} / \mathrm{dia}$. Porém, as dietas com maior nível de torta de girassol obtiveram ganho de peso médio inferior aos demais níveis de torta de girassol.

Furusho-Garcia et al. (2000) relataram ganhos 0,195kg/dia em cordeiros do mesmo genótipo em confinamento, trabalhando com dietas contendo $60,0 \%$ ou mais de concentrado, semelhante ao usado neste trabalho, que foi de $66,0 \%$. 
Desempenho, consumo...

Tabela 3. Desempenho produtivo de cordeiros alimentados com teores crescentes de inclusão de torta de girassol na ração

\begin{tabular}{|c|c|c|c|c|c|c|c|c|}
\hline \multirow{2}{*}{ Variáveis } & \multicolumn{5}{|c|}{ Teores de torta de girassol (\%) } & \multirow[b]{2}{*}{$\mathrm{R}$} & \multirow[b]{2}{*}{$\mathrm{P}$} & \multirow[b]{2}{*}{$\mathrm{CV} \%$} \\
\hline & 0 & 20 & 40 & 60 & 80 & & & \\
\hline Peso vivo inicial (kg) & 21,48 & 21,51 & 21,38 & 21,52 & 21,38 & - & 1,0000 & 24,25 \\
\hline Peso vivo final (kg) & 36,50 & 33,97 & 32,53 & 30,88 & 28,88 & - & 0,2606 & 18,03 \\
\hline Ganho peso médio diário (kg) & 0,252 & 0,204 & 0,182 & 0,153 & 0,123 & $\mathrm{~L}^{1}$ & 0,0001 & 18,98 \\
\hline Consumo MS (kg/dia) & 1,287 & 1,175 & 1,208 & 0,998 & 0,973 & - & 0,6250 & 23,75 \\
\hline Consumo MS (\% PC) & 4,390 & 4,260 & 4,390 & 3,880 & 4,030 & - & 0,7119 & 12,51 \\
\hline Consumo MS (kg/PC $\left.{ }^{0,75}\right)$ & 0,121 & 0,116 & 0,119 & 0,103 & 0,106 & - & 0,5566 & 13,17 \\
\hline Conversão alimentar & 4,760 & 5,240 & 5,910 & 5,010 & 4,920 & - & 0,8429 & 25,44 \\
\hline
\end{tabular}

CV: coeficiente de variação; R: regressão; P: probabilidade; L: linear; PC: peso corporal; PC ${ }^{0,75}$ : peso metabólico; $\hat{y}^{1}=0,275-0,03093 x\left(R^{2}=0,64\right)$.

O consumo de MS kg/dia, MS \%peso corporal e MS kg/peso metabólico (Tab. 3) não foi influenciado pela dieta $(\mathrm{P}>0,05)$, porém, em valores absolutos, pode ser observada uma diminuição do consumo nos tratamentos com maiores teores de torta de girassol, podendo explicar o menor ganho de peso médio diário em animais recebendo dietas com maiores teores de torta de girassol.

Segundo Mertens (1987), quando a densidade energética da dieta é elevada (baixa concentração de FDN) em relação às exigências do animal, o consumo pode ser limitado pela demanda energética, não ocorrendo repleção ruminal.

Dentro desse contexto, Fontenele et al. (2011) relataram que, quando o consumo é limitado pela demanda fisiológica de energia, a melhor forma de expressá-lo é com base no consumo por peso metabólico (MS/kg/PC ${ }^{0,75}$ ). No presente estudo, houve um consumo de $15,87 \%$ superior da dieta controle $(0 \%$ torta de girassol) em relação à dieta com maior teor de torta de girassol (80\% torta de girassol).

O maior teor de lipídeos presente na dieta dos animais que ingeriram as quantidades mais elevadas de torta de girassol (Tab. 2) pode ter contribuído para a redução do consumo de MS e na diminuição da digestibilidade da fibra. Os ruminantes são relativamente intolerantes a altos níveis de gordura, e o consumo de alimento usualmente diminui quando os níveis de gordura excedem 6\% na dieta (Palmquist, 1994).

Pode ter ocorrido uma redução na digestibilidade da FDN, decorrente da inibição do crescimento de bactérias e do recobrimento físico da fibra por lipídeos, que dificulta a ação dos microrganismos (Doreau e Chilliard, 1997). Observa-se que o teor de EE na dieta dos animais variou entre 57,0 a $95,4 \mathrm{~g} / \mathrm{kg}$ de MS (Tab. 2).

Lage et al. (2010) observaram efeito linear decrescente dos níveis de glicerol sobre o consumo de MS e ganho de peso médio diário, em cordeiros Santa Inês em confinamento, devido aos níveis de gordura na dieta, que variaram de 30,4 a $82,5 \mathrm{~g} / \mathrm{kg}$ de $\mathrm{MS}$.

Em relação ao não enchimento do rúmenretículo, também é provável que o tamanho da fração de fibra de torta de girassol, que foi finamente moído para compor as rações, tenha promovido trânsito normal no tubo digestivo sem causar enchimento ruminal, conforme descrito por Agy et al. (2012). Os pesquisadores também não encontraram diferença no consumo de MS em caprinos Bôer com inclusão de torta de girassol nas proporções de 0,0; 8,0; 16,0 e 24,0\% da MS da dieta.

A média de consumo de MS/dia foi de $1,128 \mathrm{~kg}$ (Tab. 3). Resultados de consumos superiores, de aproximadamente $1,250 \mathrm{~kg}$ de MS/dia, foram encontrados por Neiva et al. (2004), em experimento com cordeiros Santa Inês, não castrados, com 19,0kg de peso corporal, alimentados com dieta com relação volumoso:concentrado de 30:70, próxima da utilizada neste estudo.

Os valores de conversão alimentar (Tab. 3) estão de acordo com Homem Jr. et al. (2010) e Rocha et al. (2004) para cordeiros da mesma raça em regime de confinamento. 
Tabela 4. Consumo dos componentes nutricionais em cordeiros alimentados com inclusão de torta de girassol na dieta

\begin{tabular}{|c|c|c|c|c|c|c|c|c|}
\hline \multirow{2}{*}{ Compostos nutritivos } & \multicolumn{5}{|c|}{ Teores de torta de girassol (\%) } & \multirow[b]{2}{*}{$\mathrm{R}$} & \multirow[b]{2}{*}{$\mathrm{P}$} & \multirow[b]{2}{*}{$\mathrm{CV} \%$} \\
\hline & 0 & 20 & 40 & 60 & 80 & & & \\
\hline \multicolumn{9}{|l|}{ Proteína Bruta } \\
\hline $\mathrm{g} / \mathrm{dia}$ & 269 & 235 & 230 & 184 & 178 & - & 0,2895 & 23,12 \\
\hline$\%$ do PC & 0,92 & 0,86 & 0,83 & 0,71 & 0,74 & - & 0,2974 & 14,47 \\
\hline $\mathrm{g} / \mathrm{kg} \mathrm{PC}^{0,75}$ & 25,38 & 23,40 & 22,69 & 19,10 & 19,41 & - & 0,1896 & 14,49 \\
\hline \multicolumn{9}{|l|}{ Matéria Mineral } \\
\hline $\mathrm{g} / \mathrm{dia}$ & 83,33 & 80,83 & 79,66 & 70,16 & 67,00 & - & 0,7320 & 23,32 \\
\hline$\%$ do PC & 0,30 & 0,30 & 0,28 & 0,27 & 0,28 & - & 0,9158 & 12,22 \\
\hline $\mathrm{g} / \mathrm{kgPC}^{0,75}$ & 8,13 & 7,97 & 7,86 & 7,26 & 7,29 & - & 0,7725 & 12,78 \\
\hline Fibra detergente neutro & & & & & & - & & \\
\hline $\mathrm{g} / \mathrm{dia}$ & 586 & 505 & 506 & 405 & 415 & - & 0,3883 & 23,59 \\
\hline$\%$ do PC & 2,00 & 1,83 & 1,84 & 1,57 & 1,72 & - & 0,2900 & 12,50 \\
\hline $\mathrm{g} / \mathrm{kg} \mathrm{PC} \mathrm{P}^{0,75}$ & 55,20 & 49,90 & 49,90 & 41,93 & 45,17 & - & 0,2124 & 13,20 \\
\hline Fibra detergente ácido & & & & & & - & & \\
\hline $\mathrm{g} / \mathrm{dia}$ & 330 & 297 & 343 & 255 & 268 & - & 0,6128 & 25,41 \\
\hline$\%$ do PC & 1,13 & 1,07 & 1,24 & 1,00 & 1,11 & - & 0,3124 & 12,21 \\
\hline $\mathrm{g} / \mathrm{kg} \mathrm{PC} C^{0,75}$ & 31,10 & 29,13 & 33,81 & 26,46 & 29,19 & - & 0,3358 & 13,66 \\
\hline Extrato etéreo & & & & & & - & & \\
\hline g/dia & 73,16 & 91,33 & 89,00 & 89,00 & 87,75 & - & 0,8419 & 25,09 \\
\hline$\%$ do PC & 0,24 & 0,33 & 0,32 & 0,34 & 0,36 & $\mathrm{~L}^{1}$ & 0,0244 & 10,38 \\
\hline $\mathrm{g} / \mathrm{kg} \mathrm{PC}^{0,75}$ & 6,89 & 8,90 & 8,81 & 9,21 & 9,58 & - & 0.0862 & 11.90 \\
\hline Nutrientes digestíveis totais & & & & & & - & & \\
\hline $\mathrm{g} / \mathrm{dia}$ & 803 & 798 & 796 & 708 & 702 & - & 0,9267 & 23,40 \\
\hline$\%$ do PC & 2,74 & 2,88 & 2,89 & 2,74 & 2,90 & - & 0,9305 & 10,82 \\
\hline $\mathrm{g} / \mathrm{kg} \mathrm{PC}^{0,75}$ & 7569 & 78,44 & 78,58 & 73,31 & 76,24 & - & 0,9494 & 12,04 \\
\hline
\end{tabular}

PC: peso corporal; $\mathrm{PC}^{0,75}$ : peso metabólico; CV: coeficiente de variação; R: regressão; P: probabilidade; L: linear; ${ }^{1} \hat{y}$ $=0,2716+0,00127 \times\left(\mathrm{R}^{2}=0,79\right)$.

Entre as variáveis de consumo dos componentes nutritivos, apenas o consumo de extrato etéreo em \%peso corporal apresentou aumento linear $(\mathrm{P}<0,05)$, devido ao acréscimo dessa fração com a inclusão da torta de girassol na dieta (Tab. 4).

A inclusão de torta de girassol nas dietas não afetou o consumo de $\mathrm{PB} \quad(\mathrm{P}>0,05)$ quando expresso em g/dia, \% do PC e g/kg PC ${ }^{0,75}$ (Tab. 4), devido ao fato de as dietas serem isoproteicas e o consumo de matéria seca ter sido próximo entre os animais das diferentes dietas. O consumo médio de proteína bruta foi de 219 g/dia, sendo semelhante ao valor recomendado pelo NRC (National..., 2007), que é de $200 \mathrm{~g} /$ dia. Santos et al. (2009) verificaram ingestão de 242g/dia de PB utilizando coprodutos da canola na dieta.
Não foram observadas diferenças $(\mathrm{P}>0,05)$ nos consumos de FDA e FDN (Tab. 4), já que os teores da fibra nas dietas eram próximos. Os consumos de FDN expressos em \%peso corporal estão de acordo com os valores de 0,8 a 2,2\% recomendados por Van Soest (1994) para ruminantes.

Nas variáveis perímetro torácico, altura de garupa, comprimento de perna, perímetro de perna e largura de peito (Tab. 5) não se observou diferença $(\mathrm{P}>0,05)$ entre as médias dos animais entre as dietas experimentais até o momento do abate. Pode-se então afirmar que as medidas não foram afetadas pelas diferentes rações utilizadas, respeitando um padrão comum de crescimento. 
Tabela 5. Medidas morfométricas in vivo pré-abate e índice de compacidade corporal de cordeiros alimentados com teores crescentes de inclusão de torta de girassol na dieta

\begin{tabular}{|c|c|c|c|c|c|c|c|c|}
\hline \multirow{2}{*}{ Variáveis } & \multicolumn{5}{|c|}{ Teores de torta de girassol (\%) } & \multirow[b]{2}{*}{$\mathrm{R}$} & \multirow[b]{2}{*}{$\mathrm{P}$} & \multirow[b]{2}{*}{$\mathrm{CV} \%$} \\
\hline & 0 & 20 & 40 & 60 & 80 & & & \\
\hline Condição corporal (índice 1 a 5) & 3,58 & 3,50 & 3,50 & 2,83 & 3,10 & - & 0,1628 & 17,7 \\
\hline Comprimento corporal $(\mathrm{cm})$ & 57,75 & 58,25 & 54,25 & 55,50 & 55,00 & - & 0,5672 & 7,17 \\
\hline Perímetro torácico $(\mathrm{cm})$ & 77,75 & 74,50 & 71,50 & 71,25 & 70,50 & - & 0,3896 & 7,84 \\
\hline Altura de dorso $(\mathrm{cm})$ & 73,75 & 71,25 & 65,25 & 66,50 & 65,75 & $\mathrm{~L}^{1}$ & 0,0013 & 3,95 \\
\hline Altura de garupa $(\mathrm{cm})$ & 71,25 & 69,00 & 65,50 & 67,00 & 65,00 & - & 0,2793 & 6,46 \\
\hline Comprimento de perna $(\mathrm{cm})$ & 33,25 & 30,00 & 29,75 & 30,00 & 30,00 & - & 0,1153 & 6,51 \\
\hline Perímetro de perna $(\mathrm{cm})$ & 34,25 & 33,00 & 29,25 & 29,50 & 31,00 & - & 0,0868 & 8,80 \\
\hline Largura de garupa $(\mathrm{cm})$ & 22,75 & 20,75 & 20,75 & 20,25 & 18,75 & $\mathrm{~L}^{2}$ & 0,0412 & 7,68 \\
\hline & 20,50 & 20,25 & 18 & 17,75 & & - & 0,1143 & 10,08 \\
\hline Compacidade corporal $(\mathrm{kg} / \mathrm{cm})$ & 0,58 & 0,55 & 0,53 & 0,50 & 0,49 & - & 0,1426 & 11,88 \\
\hline
\end{tabular}

CV: coeficiente de variação; R: regressão; P: probabilidade; L: linear; ${ }^{1} \hat{y}=72,650-0,10375 x\left(R^{2}=0,78\right)$; ${ }^{2} \hat{y}=22,35-0,0425\left(R^{2}=0,88\right)$.

Houve decréscimo linear $(\mathrm{P}<0,05)$ com a inclusão da torta de girassol na dieta para a altura de dorso e largura de garupa (Tab. 5). Segundo Marques et al. (2008), medidas morfométricas são pouco influenciadas pelo manejo nutricional, desde que os animais sejam abatidos com o mesmo peso. No presente estudo, apesar de não haver diferença significativa $(\mathrm{P}>0,05)$ para $\mathrm{o}$ peso vivo final, as médias foram numericamente diferentes: 36,65 (dieta com 0\% de torta de girassol) a $28,88 \mathrm{~kg}$ de peso vivo (dieta com $80 \%$ de torta de girassol), sugerindo as diferenças encontradas para altura de dorso e largura da garupa.

As médias das medidas morfométricas $(\mathrm{cm})$ encontradas neste estudo (55,75 (comprimento corporal), 73,1 (perímetro torácico), 68,5 (altura de dorso), 67,55 (altura de garupa), 30,6 (comprimento de perna), 31,4 (perímetro de perna), 20,65 (largura de garupa) e 18,85 (largura de perna)) são semelhantes às encontradas por Marques et al. (2008), de 55,75; 73,10; 68,5; 67,$55 ; 30,6 ; 31,4 ; 20,65$ e 18,85 para comprimento corporal, perímetro torácico, altura de dorso, altura de garupa, comprimento de perna, perímetro de perna, largura de garupa e largura de perna, respectivamente, em animais com peso vivo final de até $30 \mathrm{~kg}$ da raça Santa Inês.
Os valores do índice de compacidade corporal não foram afetados pelos diferentes teores de torta de girassol na dieta $(\mathrm{P}>0,05)$. De acordo com Costa Junior et al. (2006), quanto maior a compacidade corporal, maior a proporção de músculos e gordura no animal.

Segundo Bueno et al. (1999), não há variação considerável no comprimento corporal quando o animal atinge a maturação esquelética. Portanto, quando finda o crescimento ósseo dos animais, o acréscimo no valor do índice de compacidade corporal é ocasionado pela deposição de músculo e gordura. Assim, considerando a facilidade de obtenção desse índice, seria interessante determinar seu valor para a raça Santa Inês para caracterizar a idade ao abate.

Valores de correlações positivas elevados foram constatados entre as medidas morfométricas e entre estas e o peso vivo final (Tab. 6), em consonância com Costa Junior et al. (2006), obtidos em cordeiros da raça Santa Inês.

Apesar de todas as medidas terem sido altamente correlacionadas com o peso vivo final, a medida que apresentou maior correlação com o peso vivo final nos animais alimentados com torta de girassol foi o perímetro torácico. Este resultado concorda com aqueles obtidos por Koritiaki et al. (2012). 
Tabela 6. Coeficientes de correlações de Pearson entre medidas morfométricas in vivo pré-abate e peso vivo final de cordeiros confinados com dietas contendo torta de girassol

\begin{tabular}{lccccccccc} 
& $\mathrm{CC}$ & $\mathrm{PT}$ & $\mathrm{AD}$ & $\mathrm{AG}$ & $\mathrm{CP}$ & $\mathrm{PP}$ & $\mathrm{LG}$ & $\mathrm{LP}$ \\
\hline Peso vivo final & $0,738^{*}$ & $0,926^{*}$ & $0,855^{*}$ & $0,835^{*}$ & $0,740^{*}$ & $0,841^{*}$ & $0,740^{*}$ & $0,896^{*}$ \\
Comprimento corporal & & $0,657^{*}$ & $0,687^{*}$ & $0,694^{*}$ & $0,641^{* *}$ & $0,646^{*}$ & $0,536^{* *}$ & $0,704^{*}$ \\
Perímetro torácico & & & $0,742^{*}$ & $0,813^{*}$ & $0,796^{*}$ & $0,647^{*}$ & $0,668^{*}$ & $0,844^{*}$ \\
Altura de dorso & & & & $0,960^{*}$ & $0,619^{*}$ & $0,747^{*}$ & $0,649^{*}$ & $0,773^{*}$ \\
Altura de garupa & & & & & $0,805^{*}$ & $0,739^{*}$ & $0,749^{*}$ & $0,817^{*}$ \\
Comprimento de perna & & & & & & $0,700^{*}$ & $0,785^{*}$ & $0,771^{*}$ \\
Perímetro de perna & & & & & & & $0,455^{* *}$ & $0,741^{*}$ \\
Largura de garupa & & & & & & & & & $0,818^{*}$ \\
\hline
\end{tabular}

$* 1 \%$ de probabilidade; $* * 5 \%$ de probabilidade.

\section{CONCLUSÕES}

A substituição da proteína do farelo de algodão pela proteína da torta de girassol afetou negativamente o ganho de peso de cordeiros Santa Inês em confinamento. Porém, teve pouca ou nenhuma influência nos parâmetros de consumo e nas medidas morfométricas in vivo.

\section{AGRADECIMENTOS}

Os autores agradecem ao Conselho Nacional de Desenvolvimento Científico e Tecnológico (CNPq) e à Fundação Araucária pelo suporte financeiro.

\section{REFERÊNCIAS}

AGY, M.S.F.A.; OLIVEIRA, R.L.; RIBEIRO, C.V.M. et al. Sunflower cake from biodiesel production fed to crossbred Boer kids. Rev. Bras. Zootec., v.41, p.123-130, 2012.

AHMED, M.M.M.; ABDALLA, H.A. Use of different nitrogen sources in the fattening of yearling sheep. Small Rumin. Nutri., v.56, p.3945, 2005.

BACKES, R. L.; SOUZA, A.M. de; BALBINOT JUNIOR, A.A. et al. Desempenho de cultivares de girassol em duas épocas de plantio de safrinha no Planalto Norte Catarinense. Sci. Agrar., v.9, p.41-48, 2008.

BERAN, F.H.B.; SILVA, L.D.F.; RIBEIRO, E.L.A. et al. Avaliação da digestibilidade de nutrientes, em bovinos, de alguns alimentos concentrados pela técnica de três estádios. Rev. Bras. Zootec., v.36, p.130-137, 2007.
BUENO, M.S.; SANTOS, L.E.; CUNHA, E.A. et al. Avaliação de carcaças de cabritos abatidos com diferentes pesos vivos. Rev. Nac. Carne, v.24, p.72-79, 1999.

CÉSAR, M. F.; SOUZA, W.H. Carcaças ovinas e caprinas: obtenção, avaliação e classificação. Uberaba:Agropecuária Tropical, 2007. 147p.

COSTA JUNIOR, G.S.; CAMPELO, J.E.E.; AZEVEDO, D.M.M.R. et al. Caracterização morfométrica de ovinos da raça Santa Inês criados nas microrregiões de Teresina e Campo Maior, Piauí. Rev. Bras. Zootec., v.35, p.22602267, 2006.

DOREAU, M.; CHILLIARD, Y. Digestion and metabolism of dietary fat in farm animals. $B r . J$. Nutr., v.78, p.15-35, 1997.

DUTTA, N.; SHARMA, K.; NAULIA, U. Use of undecorticated sunflower cake as a critical protein supplement in sheep and goats fed wheat straw. Asian-Australas. J. Anim. Sci., v.15, p.834-837, 2002.

FONTENELE, R.M.; PEREIRA, E.S.; CARNEIRO, M.S.S. et al. Consumo de nutrientes e comportamento ingestivo de cordeiros da raça Santa Inês alimentados com rações com diferentes níveis de energia metabolizável. Rev. Bras. Zootec., v.40, p.12801286, 2011.

FURUSHO-GARCIA, I.F.; PEREZ, J.R.O.; TEIXEIRA, J.C.; BARBOSA, C.M.P. Desempenho de cordeiros Texel x Bergamácia, Texel x Santa Inês e Santa Inês puros, terminados em confinamento, alimentados com casca de café como parte da dieta. Rev. Bras. Zootec., v.29, p.564-572, 2000. 
GOES，R.H.T.B.; CERILLO, S.L.N.; LIMA, H.L. et al. Torta de girassol em substituição ao farelo de soja nos suplementos de novilhas: desempenho e características de carcaça. Rev. Bras. Saúde Prod. Anim., v.13, p.396-409, 2012.

HOMEM JR, A.C.; EZEQUIEL, J.M.B.; GALATI, R.L. et al. Grãos de girassol ou gordura protegida em dietas com alto concentrado e ganho compensatório de cordeiros em confinamento. Rev. Bras. Zootec., v.39, p.563-571, 2010.

KEARL, L.C. Nutrient requirements of ruminants in developing countries. Logan: International Feedstuffs Institute, 1982. 381p.

KORITIAKI, N.A.; RIBEIRO, E.L.A.; SCERBO, D.C. et al. Fatores que afetam o desempenho de cordeiros Santa Inês puros e cruzados do nascimento ao desmame. Rev. Bras. Saúde Prod. Anim., v.13, p.258-270, 2012.

LAGE, J.F.; PAULINO, P.V.R.; PEREIRA, L.G.R. et al. Glicerina bruta na dieta de cordeiros terminados em confinamento. Pesq. Agropec. Bras., v.45, p.1012-1020, 2010.

MADRUGA, M.S.; SOUSA, W.H.; ROSALES, M.D et al. Qualidade da carne de cordeiros Santa Inês terminados com diferentes dietas. Rev. Bras. Zootec., v.34, p.309-315, 2005.

MARQUES, A.V.M.; COSTA, R.G.; SILVA, A.M.A. et al. Feno de flor de seda (Calotropis procera $\mathrm{SW}$ ) em dietas de cordeiros Santa Inês: Biometria e rendimento dos componentes nãoconstituintes da carcaça. Rev. Bras. Cienc. Agrar., v.3, p.85-89, 2008.

MERTENS, D.R. Predicting intake and digestibility using mathematical models of ruminal function. J. Anim. Sci., v.64, p.15481558, 1987.

MIZUBUTI, I.Y.; PINTO, A.P.; PEREIRA, E.S.; RAMOS, B.M.O. Métodos laboratoriais de avaliação de alimentos para animais. Londrina: EDUEL, 2009. v.1, 228p.
NATIONAL Research Council - NRC. Nutrient requirement of small ruminants: sheep, goats, cervids and new world camelids. Washington: National Academy Press, 2007. 384p.

NEIVA, J.N.M.; TEIXEIRA, M.; TURCO, S.H.N. et al. Efeito climático sobre parâmetros produtivos e fisiológicos de ovinos Santa Inês mantidos em confinamento na região litorânea do Nordeste do Brasil. Rev. Bras. Zootec., v.33, p.668-678, 2004.

OSÓRIO, J.C.S.; OSÓRIO, M.T.M. Produção de carne ovina: Técnicas de avaliação "in vivo" e na carcaça. 2.ed. Pelotas: Ed. Universitária PREC/UfPel, 2005. 82p.

PALMQUIST, D.L. The role of dietary fats in efficiency of ruminants. Conference: regulating lipids metabolism to increase productive efficiency. J. Nutr., v.124, p.1377-1382, 1994.

ROCHA, M.H.; SUSIN, I.; PIRES, A.V. et al. Performance of Santa Ines lambs fed diets of variable crude protein levels. Sci. Agric., v.61, p.141-145, 2004.

SANTOS, V.C.; EZEQUIEL, J.M.; PINHEIRO, R.S.B. et al. Características de carcaça de cordeiros alimentados com grãos e subprodutos da canola. Acta Sci. Anim. Sci., v.31, p.389-395, 2009.

STATISTICAL analysis system user's guide SAS Institute.. Version 8.02. Cary: Statistical Analysis System Institute, 2001.

VAN SOEST, P.J. Nutritional Ecology of the Ruminant. 2. ed. Ithaca, New York: Cornel University Press, 1994. 476p.

YÁÑEZ, E.A.; RESENDE, K.T.; FERREIRA, A.C.D. et al. Utilização de medidas biométricas para predizer características da carcaça de cabritos Saanen. Rev. Bras. Zootec., v.33, p.1564-1572, 2004. 